\title{
Translocation of Motile Cells of the Gliding Bacterium Cytophaga johnsonae Depends on a Surface Component that May Be Modified by Sugars
}

\author{
By RICHARD H. WOLKIN AND JACK L. PATE* \\ Department of Bacteriology, University of Wisconsin, Madison, WI 53706, USA
}

(Received 29 March 1984; revised 30 May 1984)

\begin{abstract}
Twenty-three sugars and sugar derivatives prevent the spread of colonies of the gliding bacterium Cytophaga johnsonae on $1.5 \%$ agar gels. Concentrations of sugars that inhibit colony spread have no inhibitory effect on motility or growth of cells. Observations of patterns of colony spread on plates with pre-established concentration gradients of sugars indicate that cells of $C$. johnsonae do not exhibit a chemotactic response to compounds that inhibit their spread. Inhibitory compounds were placed into three groups based on their relative effectiveness as inhibitors. Both metabolizable and non-metabolizable sugars served as inhibitors, it was not necessary for a sugar to be transported into the cell to inhibit, and the effectiveness of a sugar as an inhibitor did not correlate with its ability to support growth. The inorganic ions $\mathbf{M g}^{2}{ }^{\bullet}, \mathrm{Ca}^{2+}$ and $\mathrm{SO}_{4}^{2-}$ also inhibit colony spread on $1.5 \%$ agar gels. All the evidence taken together suggests that inhibitors of spread produce their effects by modifying the properties of a surface slime. The observations reported here help to give an experimental definition to two components of the gliding motility system of $C$. johnsonae: the motility "machinery' that is responsible for an actively moving cell surface and is not affected by the presence of sugars, and an extracellular component which is sensitive to sugars and which is required for translocation of cells with moving surfaces.
\end{abstract}

\section{INTRODUCTION}

Under appropriate conditions of incubation on agar gels, cells of Cytophaga johnsonae produce flat, spreading colonies characteristic of gliding bacteria. Stanier (1946) reported that high concentrations of peptone added to growth medium inhibited motility of $C$. johnsonae cells, resulting in the production of raised, non-spreading colonies. Other investigators have reported that increased concentrations of nutrients inhibit motility of other gliding bacteria (Burchard, 1981; Christensen, 1977; Duxbury et al., 1980; Garnjobst, 1945; Henricksen, 1972; Stanier, 1946). But recently it was reported that certain metabolizable sugars when added to agar media completely prevented colony spread of $C$. johnsonae cells without having any effect on their motility (Chang \& Pate, 1981). It was speculated that sugars that serve as chemoattractants might block the spread of motile cells when added to the agar plates in concentrations sufficiently high to prevent the establishment of a concentration gradient by the metabolizing cells, or that metabolism of the sugars might induce synthesis of surface polymers that impede cell translocation over an agar surface, or that sugars might somehow interfere directly with the ability of motile cells to spread over the agar gel. This investigation grew out of attempts to distinguish the correct explanation among these possibilities, and the results we report here strongly suggest that cells of $C$. johnsonae do not exhibit a chemotactic response to sugars and

\footnotetext{
Abbretiations: EC medium, enriched cytophaga medium; PB, phosphate buffer ( $5 \mathrm{mM}, \mathrm{pH} 7 \cdot 1)$; SD, minimal medium.
} 
that a wide range of sugars and sugar derivatives interfere with colony spread of motile cells by a mechanism involving modification of the physical properties of extracellular slime.

Throughout this paper we will use the terms motility, translocation and colony spread to refer to specific phenomena. Colony spread refers to the movement of a mass of cells outward from the inoculated area. Motility refers to the ability of individual cells to perform any of various kinds of movements (spin, pivot, somersault, translocate) as determined by phase-contrast microscopy of cells in a wet mount on a glass slide. Translocation refers to the movement of an individual cell in a direction parallel with its long axis from one point to another over a surface (agar, glass or other). It is important to keep these distinctions in mind when considering how sugars inhibit colony spread. Cells in a spreading colony are obviously motile and capable of translocation, but it is not necessarily true that cells in a non-spreading colony are non-motile or unable to translocate.

\section{METHODS}

Organisms. Cytophaga johnsonae UW101, a laboratory strain derived from a single colony of $C$. johnsonae (ATCC 179061) was used throughout these studies. Test phages $\phi \mathrm{CJ} 10, \phi \mathrm{CJ} 11, \phi \mathrm{CJ} 23, \phi \mathrm{CJ} 27, \phi \mathrm{CJ} 28$ and $\phi \mathrm{CJ} 30$ were described previously (Pate et al., 1979).

Media. Cells were routinely grown in enriched cytophaga (EC) medium (Chang \& Pate, 1981), which contains, per litre distilled water, $2.0 \mathrm{~g}$ tryptone (Difco), $0.5 \mathrm{~g}$ yeast extract, $0.5 \mathrm{~g}$ beef extract, and $0.2 \mathrm{~g}$ sodium acetate. The composition of a defined minimal medium (SD) (Chang \& Pate, 1981) that was also used is as follows: $0.1 \%$ $\mathrm{NH}_{4} \mathrm{Cl}, 0.5 \mathrm{~mm}-\mathrm{MgSO}_{4}, 0.2 \mathrm{~mm}-\mathrm{CaCl}_{2} .2 \mathrm{H}_{2} \mathrm{O}, 0.05 \mathrm{~mm}-\mathrm{FeSO}_{4} .7 \mathrm{H}_{2} \mathrm{O}, 0.4 \mathrm{~mm}-\mathrm{EDTA}, 20 \mathrm{~mm}$-potassium phosphate buffer ( $\mathrm{pH} 7.25$ ) and sugars were added as indicated. For $\mathrm{SD}$ agar plates, the $\mathrm{CaCl}_{2} .2 \mathrm{H}_{2} \mathrm{O}$ was omitted. In most cases, experiments to determine effects of various solutes on colony spread used EC medium, SD medium or potassium phosphate buffer (5 mM, pH 7.1) (PB) solidified with Bacto-agar added to $1 \cdot 5 \%(w / v)$. Effects of solutes on colony spread were also determined on EC medium solidified with one of the following: Bacto-agar, 0.7\%; Gelrite (Kelco, San Diego, Calif., USA), 0.4\% plus $\mathrm{MgCl}_{2} .6 \mathrm{H}_{2} \mathrm{O}, 0.08 \%$; agarose type Il (Sigma), 0.7\%. All test chemicals were filter-sterilized $(0.45 \mu \mathrm{m}$ filters, Millipore) separately and added to the appropriate media just before pouring the assay plates.

Preparation of bacteria for experiments to determine colony spread and for determination of sugar transport. Cells from mid-exponential growth ( $50-80 \mathrm{Klett}$ units, 1.4-2.0 $\times 10^{9}$ cells $\mathrm{ml}^{-1}$ ) in EC broth (4 ml) grown at $25^{\circ} \mathrm{C}$ were centrifuged for $10 \mathrm{~min}$ at $10000 \mathrm{~g}$ using a Sorvall refrigerated $\left(4^{\circ} \mathrm{C}\right)$ centrifuge. After discarding the supernatant solution, the pellet was washed by resuspension in $5 \mathrm{ml}$ ice-cold potassium phosphate buffer $(5 \mathrm{~mm}, \mathrm{pH} \mathrm{7 \cdot 1)}$ and centrifuged again. The wash was repeated once more, and the final pellet was suspended in potassium phosphate buffer to $50 \mathrm{Klett}$ units $\left(1.4 \times 10^{9}\right.$ cells $\left.\mathrm{ml}^{-1}\right)$.

Colony spread on gradiemt plates. First, $3 \mathrm{ml} \mathrm{PB}$ agar medium containing a test sugar or amino sugar (0.1 $\mathrm{M})$ was added along one edge of a $100 \mathrm{~mm}$ Petri dish, allowed to solidify and left for $4 \mathrm{~h}$ at $25^{\circ} \mathrm{C}$. Then $10 \mathrm{ml} \mathrm{PB}$ agar without a test carbohydrate was poured onto the remaining area of the Petri plate and allowed to stand at $25^{\circ} \mathrm{C}$ for $4 \mathrm{~h}$. In these gradient plates, sugar-containing agar is referred to as the 'front'. Using a multi-point inoculator, five droplets of a cell suspension were inoculated along a diagonal away from the front. The distance between the centres of adjacent spots was approximately $17 \mathrm{~mm}$. The first spot was approximately $10 \mathrm{~mm}$ from the front (see Fig. 1a). The inoculated plates were incubated at $25^{\circ} \mathrm{C}$ for $36 \mathrm{~h}$. The colonies were then observed and measured using phase-contrast microscopy.

Colony spread on solid media containing uniform concentrations of a test chemical. Approximately $5 \mathrm{ml}$ of a test medium were poured into a $45 \mathrm{~mm}$ Petri plate and left at $25^{\circ} \mathrm{C}$ for 8 to $12 \mathrm{~h}$. A $3 \mu \mathrm{l}$ sample of the cell suspension was spotted at the centre of each test plate using an Eppendorf pipette. The inoculum was absorbed into the agar gel within $2 \mathrm{~h}$, at which time the diameter of the inoculated area on each test plate was measured using the calibrated scale on the stage of a Zeiss phase-contrast microscope in conjunction with a Sony video recorder and a Hitachi television monitor. The diameter of the inoculated area was $4.7 \mathrm{~mm} \pm 0.5 \mathrm{~mm}$ on all test plates. The small variation had no significant effect on the spreading rates calculated from later measurements. Plates were then incubated at $25^{\circ} \mathrm{C}$ for 16 or $24 \mathrm{~h}$ (as indicated in Results) and the diameters of the spreading colonies were measured as before. In all cases where pre-grown cells were deposited on surfaces of gels to produce concentrated masses of cells, the deposited mass is referred to as a colony, although these are not colonies in the true meaning of the word, not having arisen in situ. For rate calculations, $2 \mathrm{~h}$ was taken as the initial time point since no increase in colony diameter was observed until this time. Two test plates were used for each experimental condition, and the variation of diameters on duplicate plates was never greater than $18 \%$, and in most cases less than $10 \%$.

Attempts to isolate non-inhibited mutants. Since first observing (Chang \& Pate, 1981) that sugars inhibit colony spread of $C$. johnsonae, we routinely incorporate glucose into solid EC media to prevent spread and to facilitate plate counts. Consequently, over the past two years we have screened thousands of non-spreading colonies on 
glucose-containing plates without ever observing mutants whose spread is not inhibited by glucose. In addition to routine screenings of colonies on EC-glucose plates, efforts were made to isolate non-inhibited mutants by inoculating EC $1.5 \%$ agar plates containing $10 \mathrm{~mm}$-glucose or sucrose with cells streaked in a large cross on the surface of each plate. Plates were incubated in moist chambers at $25^{\circ} \mathrm{C}$ for up to two weeks and inspected periodically for flares extending out from the central lines of immobilized cells. Both mutagenized and untreated populations of cells were used in these experiments. Cells were mutagenized by incubation at $25^{\circ} \mathrm{C}$ with shaking for $30 \mathrm{~min}$ in phosphate buffer $\left(5 \mathrm{mM}\right.$, pH 7.1) containing $200 \mu \mathrm{g} N$-methyl- $N^{\prime}$-nitro- $N$-nitrosoguanidine (NG) $\mathrm{ml}^{-1}$. In different experiments, this treatment resulted in the death of 96 to $97 \%$ of the cells. Treated cells were washed once and resuspended in phosphate buffer for viability counts and for use in mutant isolations. In addition to cross-streaking on glucose- or sucrose-containing plates, mutagenized cells were plated on EC-sucrose agar after appropriate dilution to give rise to individual colonies. These plates were incubated in moist chambers and examined periodically over a two week period for spreading colonies.

Assays for movement and translocation of inditidual cells. Cells taken from broth cultures (EC or SD) and examined on glass slides by phase-contrast microscopy attach to surfaces of the slide and cover glass and move rapidly (about $600 \mu \mathrm{m} \mathrm{min}{ }^{-1}$ ) for short distances backwards and forwards. Spinning, pivoting and somersaulting movements are also frequently seen (Pate \& Chang. 1979). Motility of cells grown in EC broth cultures containing inhibitors of colony spread was compared qualitatively with that of cells grown without inhibitors. When cells whose motility has been established by microscopy are transferred from broth cultures to the surface of a $1.5 \%$ agar gel, movement stops immediately and does not resume for $1.5 \mathrm{~h}$ or longer. During this 'adaptation' period, cells may accumulate around them a slime that is required for translocation over agar. Once the adaptation period is over, translocation of individual cells on surfaces of $1.5 \%$ agar can be observed by phase-contrast microscopy. Translocation on agar surfaces is always much slower (approximately $24 \mu \mathrm{m} \mathrm{min}^{-1}$ ) than translocation on glass surfaces, and the spinning, pivoting and somersaulting movements are never seen on agar. To determine translocation of individual cells on $1.5 \%$ agar, a cell suspension was diluted so that when spotted on agar individual cells or small groups of cells were well separated from each other. Plates were incubated at $25^{\circ} \mathrm{C}$ for $24 \mathrm{~h}$. The translocation of cells was recorded periodically using phase-contrast microscopy in conjunction with a video-tape recorder. Video-tape recordings were observed at 18 times actual speed.

It is not possible to determine by direct observation whether cells in non-spreading colonies are moving. since individual cells cannot be distinguished in these colonies. Therefore, cells taken from the edges of colonies on gels with or without inhibitors of colony spread were suspended in broth, placed on glass slides and examined by phasecontrast microscopy. For a reason unknown to us, populations of cells taken from the edges of colonies on agar surfaces are never as actively motile on microscope slides as those taken from broth cultures. That is, many fewer cells in any field are likely to be moving when cells are taken from agar surfaces than from broth. Therefore, motility of cells from solid media with or without inhibitors was compared by counting numbers of moving cells per total cells counted in three different fields for each condition tested.

Ability of C. johnsonae to utilize various test chemicals as sole carbon and energy sources. A $4 \mathrm{ml}$ sample of SD broth containing a test compound added to a concentration of $50 \mathrm{~mm}$ was inoculated with $0.1 \mathrm{ml}$ of a late exponential phase EC broth culture of $C$. johnsonae and incubated for up to $72 \mathrm{~h}$ or until the optical density reached approximately $100 \mathrm{Klett}$ units. Then $4 \mathrm{ml}$ of fresh SD broth containing $50 \mathrm{~mm}$ of the same test compound was inoculated with $0.1 \mathrm{ml}$ from the $72 \mathrm{~h}$ culture and incubated at $25^{\circ} \mathrm{C}$ as before. A final $1 \mathrm{ml}$ transfer was made into $25 \mathrm{ml}$ fresh SD broth with a test compound, incubated with shaking at $25^{\circ} \mathrm{C}$, and growth was monitored by measuring the increase in Klett units over a $48 \mathrm{~h}$ incubation period. If an increase of less than $5 \mathrm{Klett}$ units was observed, the test substrate was considered incapable of serving as a sole carbon and energy source. Growth rates were determined for those compounds serving as sole carbon and energy sources.

Phage sensitivity of cells grown under conditions that allow or inhibit spread. Cells of $C$. johnsonae were grown to 8090 Klett units in EC broth, EC broth containing $100 \mathrm{~mm}$-glucose, and EC broth containing $100 \mathrm{~mm}$-sucrose. Additional cultures were grown as confluent lawns on EC agar containing 100 mM-glucose and EC $1.5 \%$ agar containing $100 \mathrm{~mm}$-sucrose for $12 \mathrm{~h}$ at $25^{\circ} \mathrm{C}$. In some experiments plate-grown cells were suspended in EC broth to approximately $90 \mathrm{Klett}$ units, and $0.1 \mathrm{ml}$ volumes of all cultures were then spread onto fresh EC agar medium or EC agar containing $100 \mathrm{~mm}$ of the test sugar as was present in the preceding culture conditions. In addition, some plate-grown cells were removed from the agar surface using a glass rod and spread directly onto fresh agar medium. Test phage lysates were then spotted onto lawns of $C$. johnsonae. After approximately $24 \mathrm{~h}$ incubation at $25^{\circ} \mathrm{C}$ the plates were examined for zones of lysis. The ability of individual phage particles of $\phi \mathrm{CJ} 30$ to form plaques on lawns arising from cells pre-grown under the above conditions was also tested. Approximately $10^{8}$ cells were suspended in $4 \mathrm{ml}$ of an EC overlay agar (0.7\% agar) with and without $100 \mathrm{~mm}$-sucrose or glucose. Approximately $100 \phi \mathrm{CJ} 30$ particles were added to each of these suspensions which were then immediately vortexed and poured onto EC agar with and without a test sugar. For each condition tested, plates were set up in triplicate. Plaques were counted after $24 \mathrm{~h}$ incubation at $25^{\circ} \mathrm{C}$.

Uptake of glucose and sucrose. Cell suspensions prepared as described above were used in the assays described 
here. The uptake assay mixture $(1.0 \mathrm{ml})$ contained $5 \mathrm{~mm}$-phosphate buffer $(\mathrm{pH} 7 \cdot 1), 0.1 \mathrm{mu}$-phenazine methosulphate, $20 \mathrm{~mm}$-ascorbate, $0.5 \%$ ethanol, $62 \mu \mathrm{g}$ cell protein and $100 \mu \mathrm{M}-{ }^{14} \mathrm{C}$ substrate. The specific activity of each substrate was $50 \mu \mathrm{Ci}(1850 \mathrm{kBq}) \mu \mathrm{mol}^{-1}$. Prior to the addition of $\left[{ }^{14} \mathrm{Clsubstrate}\right.$, the assay mixture was incubated at $25^{\circ} \mathrm{C}$ and vigorously aerated with water-saturated oxygen for $2 \mathrm{~min}$. After adding the $\left[{ }^{4} \mathrm{C}\right]$ substrate, $100 \mu \mathrm{l}$ samples were removed after $0 \cdot 5,1,1 \cdot 5,2,3,5$ and 10 min incubation. The reaction was terminated by diluting each sample in $4 \mathrm{ml} 5 \mathrm{~mm}$-phosphate buffer and rapidly filtering the mixture through a Millipore HAWP $(0.45 \mu \mathrm{m})$ membrane filter. The reaction tube was washed with an additional $4 \mathrm{ml} 5 \mathrm{~mm}$-phosphate buffer and filtered as before. The membrane filters were dried under a heat lamp, placed into $10 \mathrm{ml}$ scintillation fluid containing (per litre of toluene) $0.1 \mathrm{~g}$ 1,4-bis-2-(5-phenyloxazolyl)benzene and $4 \mathrm{~g}$ 2,5-diphenyloxazole in glass scintillation vials, and counted at approximately $93 \%$ efficiency in a Packard liquid scintillation spectrometer.

Protein determination. Protein assays were done using the Bio-Rad protein assay kit (Bio-Rad) (Bradford, 1976).

Calculations of rates of spread, uptake rates and analysis of variance of cell motility. Lines of best fit were determined by least-squares linear regression. Analysis of variance and least-squares linear regression were done using Minitab computer software (Madison Area Computer Center, Madison, Wis., USA).

\section{RESULTS}

\section{Colony spread on gradient plates}

Fig. $1(a)$ represents colonies grown from spot inoculations along a diagonal away from the glucose front on a PB gradient plate. The sparse growth of cells on these plates resulted in colonies whose outlines were difficult to make out at low magnifications, so that photographs of
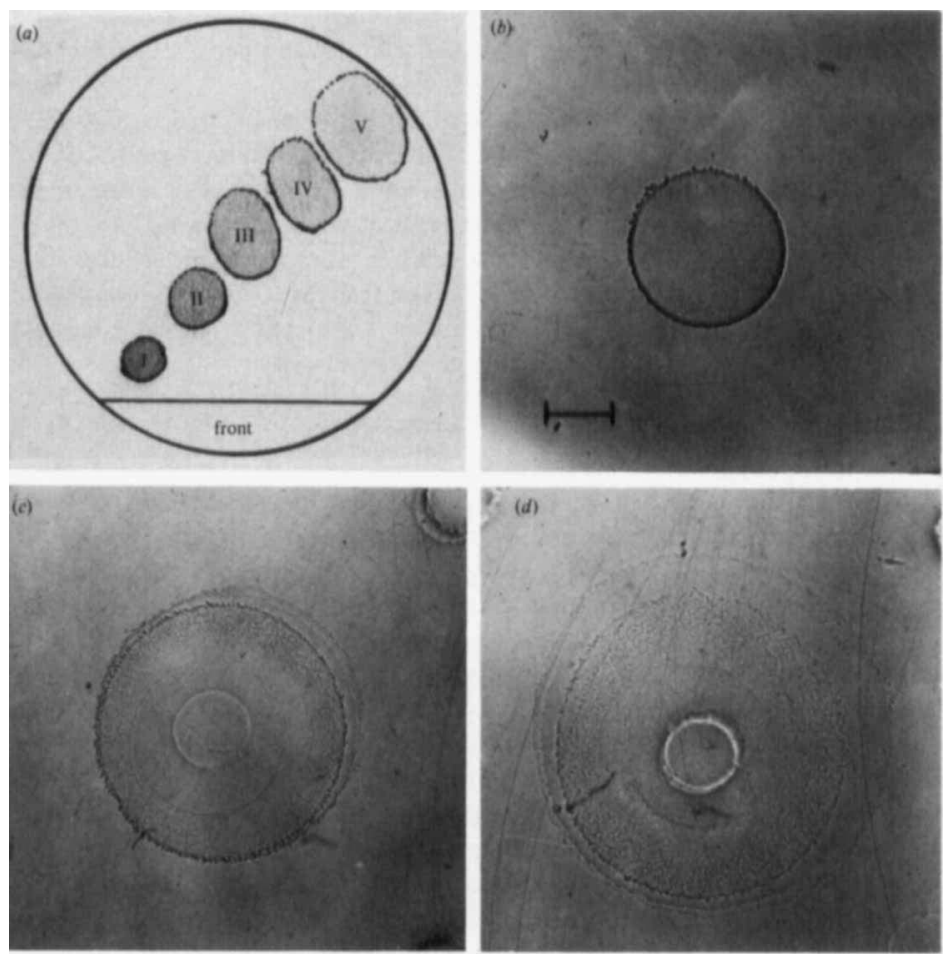

Fig. 1. Spreading colonies of $C$. johtsonae on a PB gradient plate containing a 0.1 M-glucose front. Plates were incubated at $25^{\circ} \mathrm{C}$ for $24 \mathrm{~h}$. (a) Diagrammatic representation of a gradient plate. The region labelled 'front' indicates the area of the plate to which 0.1 M-glucose in PB was initially added. I, II, III, IV and $V$ indicate the position of each colony relative to the glucose front. (b) Photomicrograph of colony I, (c) colony II, (d) colony III. The colonies in $(b),(c)$ and $(d)$ are positioned so that the front is towards the bottom of the figure. Note the progressive increase in colony diameter as the distance from the glucose front increases. Each colony also shows greater spread on the edge farthest from the glucose front. The bar represents $2.5 \mathrm{~mm}$. 
the whole plates are not useful. The diagram was prepared from a tracing of colonies grown on a glucose gradient plate and gives a representation of the relative sizes of colonies at varying distances from the front. In the following description of individual colonies, Roman numerals identify the colony positions on the gradient plate as indicated in Fig. I (a). Colony I, nearest the front, was the smallest of the five, and colony diameter increased with distance from the front. Colony I (Fig. I b) showed several small projections from the edge facing away from the glucose front, but there was little or no spread of cells beyond the area inoculated. Cells in colony II (Fig. 1c) spread in all directions from the area originally inoculated but moved a greater distance in the direction away from the glucose front. Cells in colony III spread still more in all directions than did those in colony II, and again cells moved a greater distance on the side of the colony away from the front than towards it. Colonies IV and V (not shown) appeared similar to colony III but were slightly larger in diameter. It is obvious that the pattern and extent of colony spread was influenced by the glucose concentration gradient established on this plate, and it is clear that there was no concentration of glucose that stimulated the cells to move preferentially up the gradient, towards the glucose front. Results similar to the ones described here were obtained when maltose or $N$-acetylglucosamine gradient plates were prepared. Gradient plates prepared with fructose, mannose, galactose or xylose were similar in that the diameters of colonies increased with distance from the front and cells in each colony always moved a greater distance on the side away from the front than the side facing the front. However, on these plates spread of the colony closest to the front was never completely inhibited, but appeared somewhat like colony III on the glucose gradient plate.

Examination at higher magnification of cells at the edges of colonies on the glucose gradient plate reveals that as the concentration of glucose increases, the pattern of advancing cells shifts from one of a loose network of individual cells and small groups of cells to progressively larger masses of cells with no free individuals. Fig. 2 shows the edges of colonies I, II, III and IV on the glucose gradient plate. The edge of each colony closest to the front is referred to as the near edge and the one farthest from the front the far edge. Both near and far edges of colony I (Fig. $2 a, b$ ) are smooth with some small irregularities, and no individual cells are evident. The near edge of colony II (Fig. 2c) is also smooth, but the outline is very irregular with many large projections. Again, there are no individual cells free of the mass. The far edge of this same colony (Fig. $2 d$ ) is quite different. Cells are still held together in masses, but the outward moving projections are more slender than on the near side, and these projections sometimes fuse in their outermost regions, leaving unoccupied areas rather than a solid mass of cells behind. The projections of cells at the near edge of colony III (Fig. $2 e$ ) are even more slender and this trend continues on the far side of this colony (Fig. $2 \mathrm{f}$, where some individual cells can be seen. Patterns of cells at the edges of both near and far sides of colony IV approach the loose networks seen on plates with no sugar added (cf. Fig. $5 d$ ), except that the aggregates of cells are somewhat larger than when sugar is completely absent. The edges of colony $V$ (not shown) were identical to those of colony IV.

\section{Colony spread on plates with uniform concentrations of solutes}

When washed cells were inoculated at the centres of PB agar plates and incubated at $25^{\circ} \mathrm{C}$, the colonies increased in diameter at a constant rate for at least $90 \mathrm{~h}$. Cells inoculated on PB plates containing various concentrations of glucose produced colonies whose rates of spread decreased with increasing concentrations of glucose until a concentration was reached that completely inhibited spread (Fig. 3). Although each concentration of glucose (below the complete inhibitory concentration) decreased the rate of spread, the rate was always constant throughout the $90 \mathrm{~h}$ incubation period. The rates of colony spread obtained by these measurements are shown in Fig. 4 plotted on a logarithmic scale against the concentration of glucose. When plotted this way, there is seen to be an inverse linear relationship between the logarithm of the rate of spread and the concentration of glucose over part of the concentration range tested. This kind of plot is useful for comparing the effectiveness of various solutes at inhibiting colony spread under a variety of conditions. For each solute, one can determine the minimum concentration causing a significant deviation from the maximal spreading rate (the 'threshold' 

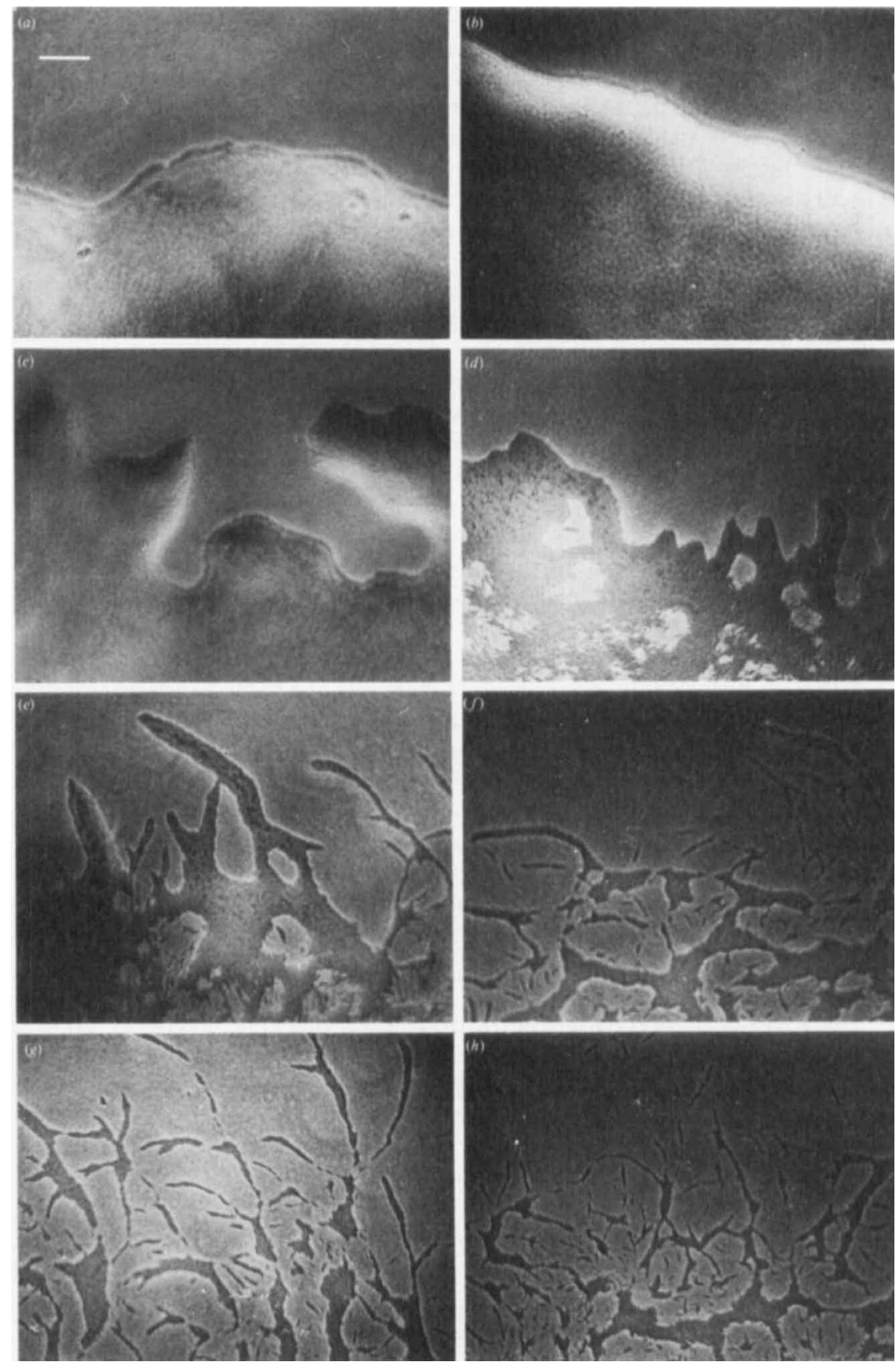

Fig. 2. Photomicrographs of edges of the colonies shown in Fig. 1. 'Near edge' refers to the edge of a colony closest to the glucose front. 'Far edge' refers to the edge of a colony farthest from the glucose front. (a) Near edge of colony I: (b) far edge of colony I: (c) near edge of colony II ; (d) far edge of colony II; (e) near edge of colony III; ( $f$ ) far edge of colony III: $(g)$ near edge of colony IV; $(h)$ far edge of colony IV. The bar represents $50 \mu \mathrm{m}$.

concentration), the lowest concentration required to completely inhibit colony spread ('saturation' concentration), and a solute concentration (IC 50 ) that inhibits the colony spread by $50 \%$. That is, when the concentration of a compound is increased by the $\mathrm{IC}_{50}$ value, the rate of 


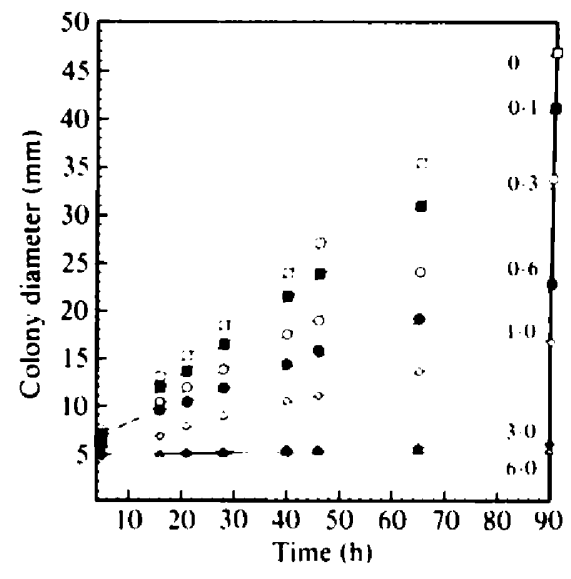

Fig. 3

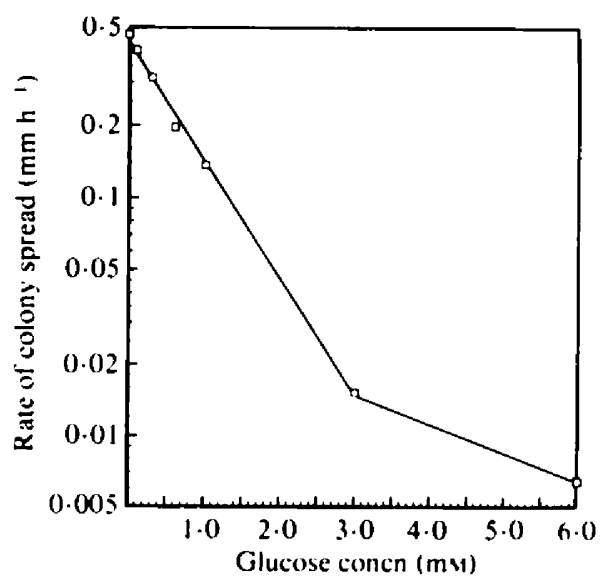

Fig. 4

Fig. 3. Effect of glucose on the rate of colony spread on $P B$ agar. Plates with varying concentrations of glucose were inoculated as described in Methods, incubated at $25^{\circ} \mathrm{C}$, and colony diameters were measured at indicated times over a period of $90 \mathrm{~h}$. The concentrations of glucose are indicated below with the corresponding rates of colony spread $\left(\mathrm{mm} \mathrm{h}^{-1}\right)$ in parentheses. $\square$. No glucose $(0 \cdot 47) ; \square$, $0.1 \mathrm{~mm}(0.40): 0.0 \cdot 3 \mathrm{~mm}(0.31): 0.0 .6 \mathrm{~mm}(0.20) ; 0.1 .0 \mathrm{~mm}(0.14) ; \bullet .3 .0 \mathrm{~mm}(0.02) ; \Delta .6 .0 \mathrm{~mm}(0.01)$.

Fig. 4. Relationship between glucose concentration and the rate of colony spread plotted on a logarithmic scale. Note the linear relationship between the threshold and saturation concentrations of glucose. The $\boldsymbol{R}$-squared value for the linear portion of the curve is $\mathbf{9 9 . 7}$.

colony spread will be decreased by $50 \%$ at any point during the linear portion of the curve.

Twenty-three sugars and sugar derivatives were compared for their inhibitory effects of colony spread on PB plates (Table 1). In these comparisons, all colonies were measured at $16 \mathrm{~h}$ incubation periods, rather than $90 \mathrm{~h}$ as for glucose-containing plates. All the test compounds listed inhibited colony spread, and the results allow placement of the compounds into three groups. Group I includes compounds whose threshold concentrations range from 0.1 to $0.4 \mathrm{~mm}$, saturation concentrations from 3 to $7 \mathrm{~mm}$, and $I C_{50}$ values from 0.7 to $1.8 \mathrm{~mm}$. The corresponding values for group III compounds are 25 to 100,400 to 750 , and 57.2 to $119.6 \mathrm{mM}$. Values intermediate to those obtained for group I and group III compounds were found for the two sugars placed in group II. Table 1 also indicates whether each of the test compounds serves as a sole source of carbon and energy for cells grown in SD medium, and for those that do support growth, comparative growth rates are indicated. There is no correspondence between the ability of a compound to support growth and its effectiveness as an inhibitor of colony spread. The rate of growth using fructose or mannose (group III sugars) is approximately the same as that supported by glucose (a group I sugar). Neither sucrose nor 1-O-methyl $\alpha$-D-glucopyranoside serves as a carbon and energy source, but both inhibit colony spread at concentrations characteristic of group I compounds, whereas seven other non-metabolizable compounds behave as group III compounds in their inhibitory properties. With the exception of glucose 6phosphate and glucoheptose, all sugars listed in Table I which did not support growth of $C$. johnsonae were tested for their effects on growth when added at $100 \mathrm{~mm}$ to EC medium. None of the sugars inhibited growth.

It was shown earlier (Chang \& Pate, 1981) that $\mathrm{Mg}^{2+}, \mathrm{Ca}^{2+}$ and $\mathrm{SO}_{4}^{2-}$ but not $\mathrm{Cl}^{-}$or $\mathrm{Na}^{+}$ inhibit colony spread of $C$. johnsonae. Threshold and saturation concentrations measured for $\mathrm{MgCl}_{2} .6 \mathrm{H}_{2} \mathrm{O}, \mathrm{CaCl}_{2} .2 \mathrm{H}_{2} \mathrm{O}$ and $\mathrm{Na}_{2} \mathrm{SO}_{4}$ are given in Table 1 . Of these only $\mathrm{CaCl}_{2} .2 \mathrm{H}_{2} \mathrm{O}$ inhibits cell growth at the saturation concentration when added to EC broth or SD-glucose broth. Colonies on solid media containing 25 or $50 \mathrm{mM}-\mathrm{CaCl}_{2} \cdot 2 \mathrm{H}_{2} \mathrm{O}$ contained misshapen and lysing cells, which was not true of cells on solid media containing $\mathrm{MgCl}_{2}$ or $\mathrm{Na}_{2} \mathrm{SO}_{4}$ at saturation concentrations. 
Table 1. Inhibition of colony spread by various solutes

PB plates containing uniform concentrations of a test sugar were inoculated with $3 \mu \mathrm{l}$ of a cell suspension. All test plates were incubated at $25{ }^{\circ} \mathrm{C}$ for $16 \mathrm{~h}$ at which time the diameters of the colonies were measured. Threshold and saturation values were obtained from these measurements, with $95 \%$ confidence according to Student's $t$ test.

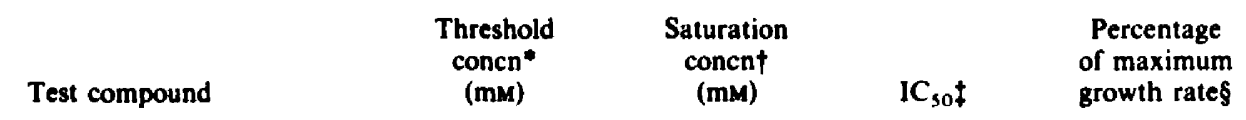

Group I

$N$-Acetylglucosamine $\quad 0$.

Glucosamine $\quad 0.1$

Glucose $\quad 0.3$

Maltose $\quad 0-4$

1-O-Methyl- $\alpha$-D-glucopyranoside $\quad 0.1$

Sucrose $\quad 0 \cdot 1$

Trehalose $\quad 0.3$

Group II

2-Deoxy-D-glucose

3-O-Methyl- $\alpha$-D-glucopyranoside 10

Group III

Arabinose $\quad 50$

Fructose $\quad 50$

D-Fucose 25

Galactose 25

D-Glucoheptose $\quad 50$

D-Gluconic acid $\quad$ so

Glucose 6-phosphate 75

D-Glucuronic acid 50

Lactose $\quad 100$

Mannose

$\alpha$-Methyl-D-mannoside $\quad 50$

D-Ribose 25

Sorbitol 25

Xylose 25

Metals

$\mathrm{MgCl}_{2} .6 \mathrm{H}_{2} \mathrm{O} \quad 0.5$

$\mathrm{NaSO}_{4}$

$\mathrm{CaCl}_{2} \cdot 2 \mathrm{H}_{2} \mathrm{O}$

5075

0.5

$\begin{array}{rrr}7 & 1.8 & 80 \\ 6 & 1.6 & 45 \\ 6 & 1.3 & 88 \\ 7 & 1.3 & 100 \\ 3 & 0.7 & \text { NG } \\ 6 & 1.4 & \text { NG } \\ 6 & 1.6 & 94 \\ & & \\ 50 & 8.6 & \text { NG } \\ 125 & 21.2 & \text { NG } \\ & & \\ 500 & 65.6 & 41 \\ 400 & 72.6 & 88 \\ \mathbf{4 0 0} & 73.6 & \text { NG } \\ 500 & 72.9 & 39 \\ 750 & 110.4 & \text { NG } \\ 500 & 58.7 & \text { NG } \\ 750 & 119.6 & \text { NG } \\ 600 & 69.0 & \text { NG } \\ 750 & 70.7 & \text { NG } \\ 400 & 58.9 & 82 \\ 500 & 78.7 & \text { NG } \\ \mathbf{4 0 0} & 70.7 & \text { NG } \\ 500 & 78.5 & \text { NG } \\ \mathbf{4 0 0} & 57.2 & 40\end{array}$

- Defined as the lowest concentration of a test chemical which inhibits colony spread compared to spread on PB agar without addition of the test compound.

$\uparrow$ Defined as the lowest concentration of a test chemical which totally inhibits colony spread on PB agar.

$\ddagger \mathrm{IC}_{50}$ represents the concentration of a solute which inhibits colony spread by $50 \%$ when added during the linear portion of the curve. The values are point estimates derived from the linear transformation of the data, i.e. the logarithm of the rate of colony spread $=b_{0}+b_{1}$ [solute] such that the $\mathrm{IC}_{30}=-\log 2 / b_{1}$. At $\alpha=0.02$ the IC so within Groups I, II and III are found to be equal, while between these groups there are significant differences. The IC $_{\text {so }}$ for the metals tested would also be considered equivalent and lie within Group II of the sugars and sugar derivatives.

$\$$ Maximum growth rate of test cultures expressed as a percentage of the highest maximum growth rate observed in SD medium; NG, no growth.

Figs $S(a),(b),(c)$ and $(d)$ show the edges of colonies spreading on PB agar containing $6 \mathrm{~mm}$-glucose, $1 \mathrm{~mm}$-glucose, $0.3 \mathrm{~mm}$-glucose and no glucose, respectively. On plates containing uniform concentrations of glucose, the pattern was the same as that seen on glucose gradient plates: as the concentration of glucose was increased, cells accumulated into larger masses and individual cells did not move away from masses of cells. With $0.3 \mathrm{~mm}$-glucose, which is just at the threshold concentration, the pattern has already shifted from the loose network typical of cells spreading in the absence of glucose (Fig. $5 d$ ) to a much tighter network consisting of small clumps of cells (Fig. $5 c$ ). With $1 \mathrm{mm-glucose,} \mathrm{even} \mathrm{small} \mathrm{clumps} \mathrm{were} \mathrm{unable} \mathrm{to} \mathrm{break} \mathrm{away} \mathrm{from}$ larger masses, and colony edges consisted of cells packed into slender, interconnecting 

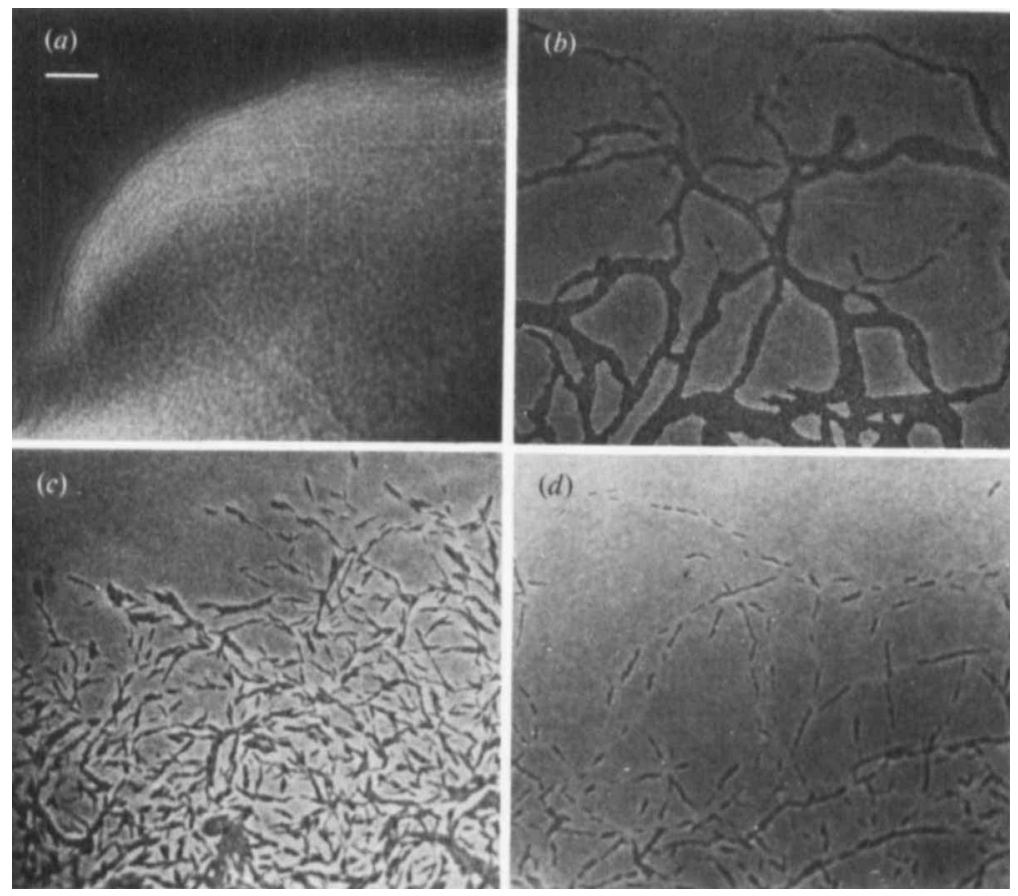

(d)

Fig. 5. Photomicrographs of edges of colonies incubated on PB agar containing (a) 6.0 mM-glucose, (b) $1.0 \mathrm{~mm}$-glucose, (c) $0.3 \mathrm{~mm}$-glucose, and $(d)$ no glucose. Plates were incubated at $25^{\circ} \mathrm{C}$ for $16 \mathrm{~h}$. The bar represents $50 \mu \mathrm{m}$.

projections from the central part of the colony (Fig. $5 b$ ). At the saturation concentration (6.0 mM) not even slender strands extended away from the colony (Fig. $5 a$ ).

\section{Effect of sucrose on translocation of individual cells on $1.5 \%$ agar}

When dilute suspensions of cells were deposited on PB $1.5 \%$ agar gels and monitored by phasecontrast microscopy, cells began to translocate after approximately $1.5 \mathrm{~h}$ incubation at $25^{\circ} \mathrm{C}$. Upon continued incubation $(24 \mathrm{~h}$ ), cell division and translocation resulted in a loose network of cells distributed over the agar surface. When cells were deposited on PB $1.5 \%$ agar containing $3 \mathrm{mM}$ - or $6 \mathrm{~mm}$-sucrose, translocation was never observed. After prolonged incubation, cell divisions resulted in the formation of microcolonies over the agar surface. Lower concentrations of sucrose $(0.3,0.6,1.0 \mathrm{~mm})$ prolonged by about $2 \mathrm{~h}$ the incubation period required for translocation to begin, the speed of translocation was greatly reduced, and relatively few cells were ever seen translocating in any field compared with cells on plates with no sucrose. As with no sucrose, $24 \mathrm{~h}$ incubation resulted in cells distributed in a loose network.

\section{Attempts to isolate non-inhibited mutants}

When EC-glucose or EC-sucrose $(1.5 \%$ agar) plates are cross-streaked with cells of $C$. johnsonae and incubated at $25^{\circ} \mathrm{C}$, luxuriant growth is observed after $24 \mathrm{~h}$. Growth is confined to the inoculated area, since colonies do not spread on these plates. A total of 290 plates were crossstreaked with untreated cells ( $10^{8}$ to $10^{9}$ cells per plate), and another 290 plates were crossstreaked with NG-mutagenized cells ( $10^{6}$ to $10^{7}$ cells per plate). No flares of spreading cells were observed on any of these plates, even after incubation for two weeks. In addition, over $\mathbf{8 0 0 0 0}$ colonies grown from NG-mutagenized cells plated on EC-sucrose agar were examined for spreading edges, but no non-inhibited mutants were found. 


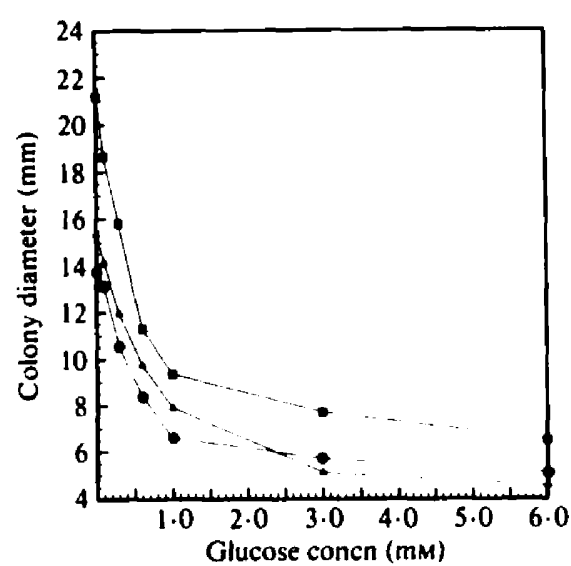

Fig. 6

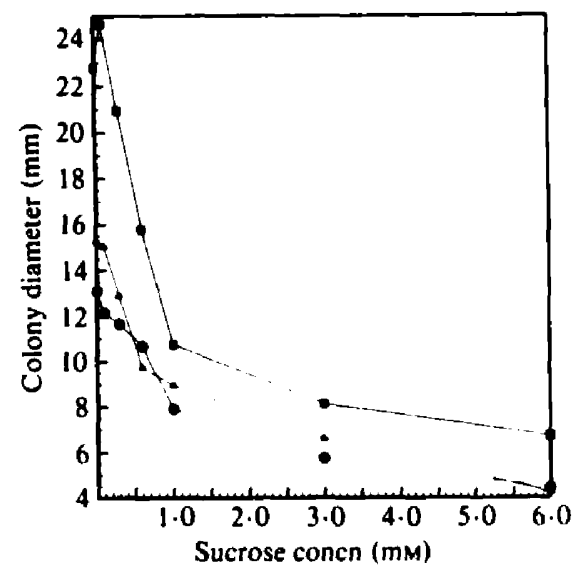

Fig. 7

Fig. 6. Effects of various concentrations of glucose on colony spread on $1.5 \%$ agar gels containing EC (D), PB (A) or SD (O) media. Colony diameters were measured after $24 \mathrm{~h}$ incubation at $25^{\circ} \mathrm{C}$. Points represent averages from two test plates as described in Methods.

Fig. 7. Effects of various concentrations of sucrose on colony spread on $1.5 \%$ agar gels containing EC (D). PB (A) or SD (O) media. Colony diameters were measured after 24 h incubation at $25^{\circ} \mathrm{C}$. Points represent averages from two test plates as described in Methods.

Effects of sugars on colony spread on different media solidified with $1.5 \%$ agar

Results of experiments to determine whether the composition of the medium influenced the inhibition of colony spread caused by glucose or sucrose are shown in Figs 6 and 7 . Of the three media tested, only EC supports good growth with no metabolizable sugar added. Growth on SD-glucose plates is greater than on PB-glucose plates, due to the presence of ammonia as a nitrogen source in the former but not in the latter. Some growth occurs on both SD and PB plates with no glucose added, due to growth-supporting contaminants present in Bacto-agar (Bretscher $\&$ Kaiser, 1978), but, as judged from the appearance of spreading colonies, the amount of growth over the $24 \mathrm{~h}$ period of incubation is approximately equivalent on PB and SD plates and is minimal when compared to growth on EC plates. Growth on EC plates is thick and luxuriant, making the spreading colonies clearly visible, whereas the flat, almost transparent colonies are difficult to see on PB and SD plates. Glucose stimulates growth when added to PB or SD media (more growth on SD than on PB) as evidenced by increased colony mass. Sucrose has no effect on growth when added to these media. Under all conditions tested, the rate of spread was greatest on EC plates and approximately equivalent on PB and SD plates. On all three media, the addition of an equivalent amount of glucose caused approximately the same percentage decrease in colony diameter $\left(\mathrm{IC}_{50}\right.$ values were within the range of 0.6 to 1.3$)$. Thus the spread of rapidly growing cells is not more or less susceptible to inhibition by sugars than is the spread of slowly growing cells incubated under nutrient-poor conditions, and there is no indication that any components of the three different media tested tend to relieve the inhibitory effects of sugars on colony spread.

\section{Effects of sucrose on colony spread on EC medium solidified with different gelling agents}

A comparison of colony spread in response to various concentrations of sucrose added to EC medium solidified with agar $(1.5 \%)$, agar $(0.7 \%)$, Gelrite $(0.4 \%)$ or agarose $(0.7 \%)$ is shown in Fig. 8. With no added sucrose, colony spread was greatest on $1.5 \%$ agar gels, reaching a diameter after $24 \mathrm{~h}$ incubation nearly twice that observed on the other three gels. As sucrose was added to increasingly higher concentrations, diameters of colonies on $1.5 \%$ agar and $0.7 \%$ agarose gels became correspondingly smaller, just as in previous experiments using $1.5 \%$ agar gels. But the diameters of colonies on Gelrite gels remained about the same throughout the concentration 


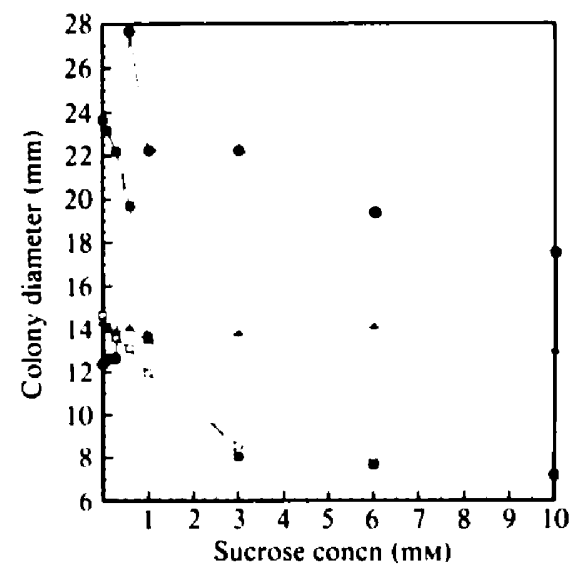

Fig. 8. Effects of various concentrations of sucrose on colony spread on EC medium solidified with different gelling agents. $\mathrm{EC}+0.7 \%$ agar;, $\mathrm{EC}+1.5 \%$ agar; $\triangle, \mathrm{EC}+0.4 \% \mathrm{Gelrite} ; \square, \mathrm{EC}+$ $0.7 \%$ agarose. Colony diameters were measured after $24 \mathrm{~h}$ incubation at $25^{\circ} \mathrm{C}$. Points represent averages from two test plates as described in Methods.
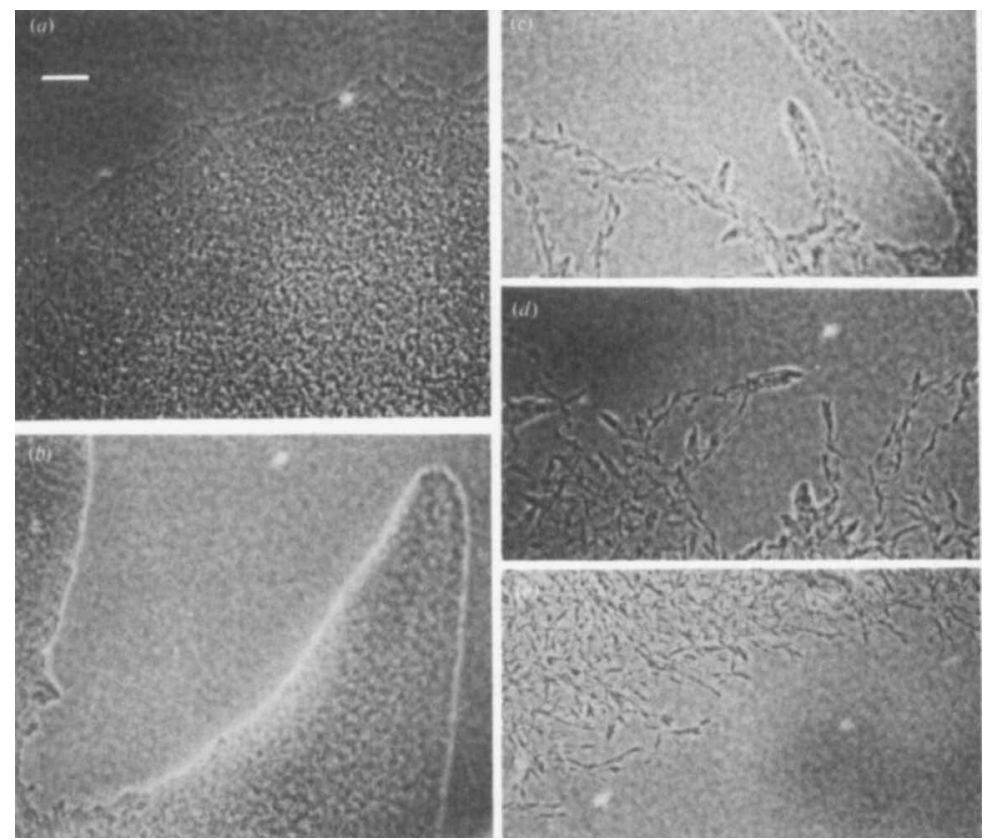

Fig. 9. Photomicrographs of edges of colonies incubated on EC (0.7\% agar) gels containing (a) $100 \mathrm{mm-}$ sucrose, (b) $10 \mathrm{~mm}$-sucrose, (c) $3 \mathrm{~mm}$-sucrose. (d) $0.6 \mathrm{~mm}$-sucrose, and (e) no sucrose. Plates were incubated for $24 \mathrm{~h}$ at $25^{\circ} \mathrm{C}$. The bar represents $50 \mu \mathrm{m}$.

range of sucrose shown. High concentrations $(100 \mathrm{~mm})$ of sucrose did decrease the diameters of colonies on Gelrite by about $50 \%$ (not shown). Diameters of colonies on $0.7 \%$ agar gels increased dramatically (from 12 to $27.5 \mathrm{~mm}$ ) with the addition of sucrose to $1.0 \mathrm{mM}$. As the concentration of sucrose was increased beyond $1.0 \mathrm{~mm}$, diameters of colonies on $0.7 \%$ agar gels gradually decreased but never to a diameter smaller than colonies on $0.7 \%$ agar gels with no added sucrose, even when sucrose was added to a concentration of $100 \mathrm{~mm}$ (not shown).

Although the effects of sucrose on colony spread differed on 0.7 and $1.5 \%$ agar gels, its effect on the pattern of cells at colony edges was similar on both gels (Figs 5 and 9). That is, as the 
concentration of sucrose increased, cells at the colony edges become progressively more aggregated into larger masses until a concentration was reached that prevented movement of single cells or small groups of cells away from the larger mass. On $0.7 \%$ agar gels without sucrose (Fig. $9 e$ ) cells were scattered at colony edges and did not move along thin lines extending far away from the colony as on $1.5 \%$ agar (Fig. $5 d$ ). The same relationship was seen on Gelrite gels.

\section{Effects of other solutes on colony spread}

Since colony spread on the three media used (EC, PB, SD) was always greatest on EC medium, some effort was made to determine which components of EC medium stimulated colony spread. Neither single amino acids, groups of amino acids, nor Casamino acids added to SD medium at any concentration stimulated colony spread, indicating that the increased colony spread on EC medium was not due to its amino acid components. These experiments also confirmed an earlier report that amino acids do not inhibit colony spread when added to solid growth media (Chang \& Pate, 1981). Attempts to increase colony spread by various salts, EDTA and organic solutes added to the PB agar failed. When tryptone was increased from $0.2 \%$ to $0.6 \%$ in EC medium, colony spread was greatly decreased, but not completely inhibited. The effects on colony spread of decreasing the tryptone concentration below $0.2 \%$ were not determined.

\section{Motility of cells growing in the presence of compounds that inhibit colony spread}

All sugars listed in Table 1, except glucose 6-phosphate and glucoheptose, were examined for their effects on the motility in wet mounts of cells grown in broth cultures at concentrations which totally inhibit colony spread. All group I compounds were tested at $100 \mathrm{~mm}$ and both group II compounds were tested at $250 \mathrm{mM}$. Group III compounds were tested at 400-500 mM. In no case was there any inhibitory effect on the motility of broth-grown cells. Furthermore, no difference could be detected between the motility of cells washed and resuspended in phosphate buffer with or without $100 \mathrm{~mm}$-glucose or sucrose. Cells growing on EC agar (1.5\%) to which 100 mm-glucose or sucrose was added were actively motile when examined in wet mounts.

\section{Phage sensitivity of cells grown in the presence of glucose or sucrose}

Evidence from previous work indicates that all phages thus far isolated against $C$. johnsonae infect only motile cells. A group of 28 phages did not infect truly non-motile mutants, and adsorption of phages was abolished when wild-type cells were treated with carbonyl cyanide $m$ chlorophenylhydrazone (CCCP), which reversibly inhibits motility (Pate et al., 1979; Chang, 1982). This work has been extended in our laboratory using the original 28 phages plus 11 more recently isolated phages and over 100 independently isolated non-spreading mutants or wildtype cells whose motility was eliminated with chemicals or by temperature adjustments $(R$. $H$. Wolkin \& J. L. Pate, unpublished observations; Chang, 1982). These phages have proved useful for determining whether mutants isolated for their inability to spread (non-spreading colonies on $1.5 \%$ agar gels) are truly non-motile and whether experimentally altered wild-type cells are motile. In all cases where non-spreading mutants have been found to be sensitive to some or all phages, they have proved by further examination to be motile non-spreading mutants rather than truly non-motile mutants. As described in Methods, cells to be tested for phage sensitivity were pre-grown in EC broth as well as in EC broth or on EC plates to which $100 \mathrm{~mm}$-glucose or sucrose had been added. Cells were pre-grown under the same conditions to be used in tests for phage sensitivity in order to ensure that any alterations induced in motility or in components of the cell surface by growth in the presence of inhibitory concentrations of sugars would already have occurred when phages were added to cells. There was no difference in sensitivity to any of the test phages as determined by spotting phages on lawns of cells with or without $100 \mathrm{~mm}$ sucrose or glucose. Furthermore, the plaque-forming efficiency of phage $\phi \mathrm{CJ} 30$ did not vary significantly on EC media with or without $100 \mathrm{~mm}$-glucose or sucrose added (using analysis of variance with triplicate values for each test condition, the $P$ value was between 0.5 and 0.75 with a pooled SD of $7 \cdot 43$ ). 


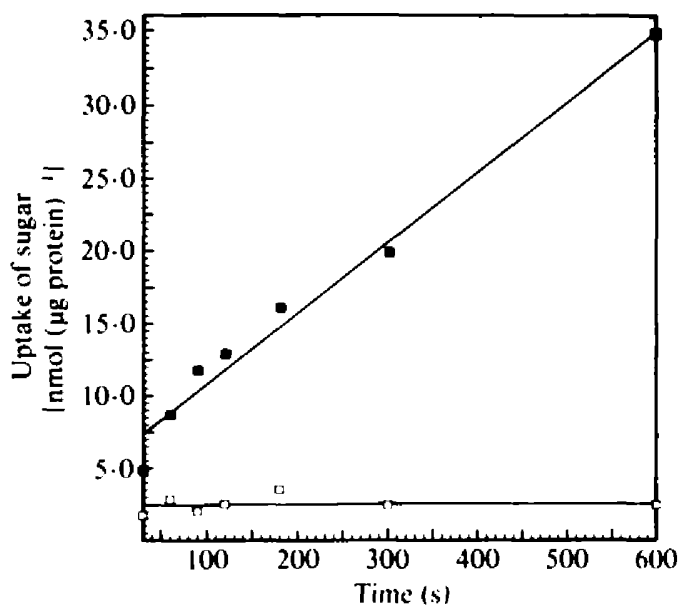

Fig. 10. Time course of uptake of glucose and sucrose by cells of $C$. johnsonae. Reaction mixtures contained per $\mathrm{ml}: 100 \mu \mathrm{l} 25 \mathrm{~mm}$-phosphate buffer (pH 7.1), $100 \mu] 1 \mathrm{~mm}$-phenazine methosulphate, $100 \mu \mathrm{l} 200 \mathrm{~mm}$-ascorbate, $100 \mu$ ] [ $\left.{ }^{1+} \mathrm{C}\right] \mathrm{sugar}, 500 \mu \mathrm{l}$ cell suspension $(0.62 \mathrm{mg}$ protein), and $100 \mu$ l distilled water. The rates of uptake were calculated from the slopes of the lines determined by the leastsquares method. G. Glucose: $\square$, sucrose.

\section{Transport of glucose and sucrose by cells of $C$. johnsonae}

Glucose was accumulated by cells over a $10 \mathrm{~min}$ time course at a constant rate of $4.9 \times$ $10^{-2} \mathrm{nmol}(\mu \mathrm{g} \text { protein) })^{-1} \mathrm{~s}^{-1}$ (Fig. 10). Addition of CCCP to the reaction mixture to $20 \mu \mathrm{M}$ completely eliminated glucose accumulation (not shown). There was no accumulation of sucrose.

\section{DISCUSSION}

Although at saturation concentrations and above all sugars and sugar derivatives tested (hereafter referred to simply as 'sugars') completely inhibited colony spread on $1.5 \%$ agar gels, cell motility was not inhibited, as determined by direct microscopical observations and by the unchanged sensitivity of sugar-treated non-spreading cells to phages that do not infect nonmotile cells. Of the 23 sugars shown to inhibit colony spread, only 10 served as sources of carbon and energy when added to a defined medium. A limited number of sugars was tested earlier (Chang \& Pate, 1981), and it was reported that of those tested only metabolizable sugars inhibited colony spread and that the only non-metabolizable sugar (lactose) tested did not. As shown in this study, all sugars tested, metabolizable or not, inhibit colony spread, and the failure of lactose to inhibit previously is now understood to be due to its high threshold concentration (100 mM). None of the 11 non-metabolizable sugars tested inhibited growth when added to EC medium (at $100 \mathrm{~mm}$ ), and it seems likely that none of them was transported, although only sucrose was tested and shown not to be transported. Sugars inhibited equally well the spread of rapidly growing cells (EC medium or SD plus glucose) and slowly growing, nutrient-starved cells (SD plus sucrose or PB plus sucrose), indicating that the metabolic state of the cells is unrelated to their sensitivity to inhibition by sugars.

It was suggested earlier (Chang \& Pate, 1981) that sugars that inhibit colony spread of $C$. johnsonae might do so as a consequence of their serving as attractants. The reasoning was that sufficiently high concentrations of an attractant incorporated into the agar gel would not be metabolized rapidly enough to establish a concentration gradient for cells to respond to, and, consequently, the direction of cell movement should be completly unbiased and cells would fail to migrate far from the point of inoculation. If this explanation were correct, then some position on the gradient established by diffusion of sugars out from the front on gradient plates should have caused preferential movement of cells toward the front, up the concentration gradient. 
Instead, the only direction of biased movement seen on any of the gradient plates was down the gradient and this is explained not by chemotactic behaviour, but by the inverse relationship between rate of colony spread and concentration of sugar. In all cases (even for group I sugars) the threshold concentrations required to inhibit colony spread were somewhat higher than would be expected for threshold concentrations of attractants to elicit positive chemotactic responses, based on threshold values of attractants for $E$. coli (Adler, 1975). Therefore, the more distant colonies from the front, whose cells were capable of traversing the agar surface, would have been expected to exhibit biased movement up the gradient if the test compound were an attractant, but none did. Clearly, the reason sugars inhibit colony spread on agar surfaces is not related to chemotaxis. Some previous reports claimed to have demonstrated chemotactic responses in other gliding bacteria (Ho \& McCurdy, 1979; Lev, 1954; McVittie \& Zahler, 1962; Shimkets et al., 1979) but more recent work makes the validity of those claims doubtful (Dworkin \& Eide, 1983), and it was pointed out that the slow rate of surface translocation of Myxococcus xanthus would make it impossible for cells to detect and respond to a concentration gradient of any test solute, since the solutes diffuse through the agar gel faster than cells move over the gel.

If sugars inhibited colony spread by effecting a change in the motile behaviour of cells or by stimulating cells to synthesize a different or altered surface polymer that immobilized cells or by inducing any other kind of change in the behaviour or biosynthetic patterns of cells, it should be possible to isolate mutants that fail to respond to the presence of sugars as wild-type cells do and whose surface translocation would therefore not be inhibited. Despite extensive searches, we have not isolated these kinds of mutants, suggesting that sugars do not inhibit the spread of wildtype cells by eliciting some response that could be modified by mutation. It also suggests that if inhibition of spread is due to modification of the properties of a cell surface component when sugars are present, then that surface component must be required for translocation over the surface of $1.5 \%$ agar gels. Otherwise, mutants lacking this surface component or with an altered component could be isolated as non-inhibited mutants.

Wherever examined, gliding bacteria have been found to produce slime, which is thought to be involved in motility, but its role in that process is unknown (Burchard, 1981; Christensen, 1977; Duxbury et al., 1980; Dworkin, 1966; Henricksen, 1972). Slime is recognized by the cohesive nature of colonies of gliding bacteria and is often deposited as slime tracks on agar surfaces over which cells move, and these tracks serve as preferred paths of movement for other cells that follow (Burchard, 1982). The nature of the substratum is also important in determining whether or not cells can translocate over it, suggesting that not only must the cell be capable of movement, but that its own surface must be capable of interacting with the surface to be traversed. For example, on agar gels the moisture level and the concentration of agar are critical factors influencing colony spread (Burchard, 1981; Garnjobst, 1945; Glaser \& Pate, 1973; Henricksen, 1972; Stanier, 1946). Agarose is not suitable for translocation of some gliding bacteria, but can be made so by the addition of a cold-water extract of agar or any of a variety of polysaccharides (Arlauskas \& Burchard, 1982).

Although the presence of extracellular slime associated with gliding bacteria is widely reported, the biochemical nature of the slime is not established. In those few cases where extracellular polymers were extracted and characterized, it was not possible to identify the extracted material as the same substance that comprises slime tracks nor to determine whether extracted polymers are required for motility. Not surprisingly, extracted materials consist of polysaccharides and glycoproteins (Humphrey et al., 1979; Johnson \& Chilton, 1966; Sutherland, 1979; Sutherland \& Thomson, 1975). A surface glycoprotein extracted from cells of Flexibacter BH3 exhibited viscous properties typical of a Stefan adhesive, properties that seem perfectly suited for adherence of a bacterium to a substratum while at the same time allowing movement through the slime (Humphrey et al., 1979). In the same report it was shown by electron microscopy of cells swarming over collodion-coated grids that extracellular material was secreted ahead and to the sides of the leading bacteria in a mass of swarming cells, suggesting that, when cells move over a surface, they are actually moving through their secreted slime. 
In general, gliding bacteria adhere to surfaces over which they move, and it seems likely that adherence is a prerequisite for gliding (Arlauskas \& Burchard, 1982; Burchard, 1981; Humphrey et al., 1979). When cells of $C$. johnsonae are examined by phase-contrast microscopy, only those cells that become attached to surfaces of the slide or cover glass exhibit active movements. Surfaces of free-floating cells are in motion, as determined by their ability to move latex spheres that come into contact with floating cells (Pate \& Chang, 1979), but cell surface motion alone does not result in translocation of cells; for this, attachment to a surface is required. Other evidence of the important role of an adhesive material in gliding and non-gliding movements of $C$. johnsonae comes from observing spinning, pivoting and somersaulting cells that become temporarily attached to glass slides (Pate \& Chang, 1979). These kinds of movements have been reported for a variety of gliding bacteria (Burchard, 1981; Henricksen, 1972; Lapidus \& Berg, 1982). Characteristics of non-spreading mutants of $C$. johnsonae also suggest that a surface slime and adherence to a surface are required for gliding motility. Some non-spreading mutants are incapable of any movement ('truly non-motile' mutants), and others are actively motile when examined on glass slides by phase-contrast microscopy but produce non-spreading colonies on $1.5 \%$ agar gels ('motile non-spreading' mutants) (Pate \& Chang, 1979; R. H. Wolkin \& J. L. Pate, unpublished observations). Non-spreading mutants with similar characteristics were also derived from Flexibacter columnaris (Glaser \& Pate, 1973). Such motile non-spreading mutants obviously possess the machinery required to keep the cell surface moving, but are defective in a surface component necessary to translate cell surface movement into translocation over an agar gel. Perhaps sugars that inhibit colony spread modify properties of surface slime in a way that is similar to alterations of slime due to mutation. If gliding motility depends on the coating of a substratum with a temporary adhesive through which cells can then translocate, any alteration of the adhesive that interferes with its coating of the substratum or that prevents translocation of cells through it would prevent colony spread.

Any explanation for the inhibitory effects of sugars on colony spread must take into account the following observations: $(a)$ sugars need not be transported or utilized; $(b)$ relatively high concentrations of sugars are required to inhibit spread; $(c)$ all sugars inhibit but some are more effective than others; $(d)$ the inhibitory effects vary depending on the nature of the gel but do not vary with different media (EC, SD, PB) added to the same gel; (e) the inhibitory compounds cause cells growing on surfaces to pack together in masses but do not inhibit motility or cause clumping of cells grown in broth cultures; $(f)$ it has not been possible to isolate mutants that spread normally in the presence of sugars (non-inhibited mutants). An explanation that is compatible with these observations is that sugars inhibit colony spread by modifying the properties of a surface polymer (slime) required for translocation, and reducing its ability to spread on an agar surface or preventing movement of cells through it. An alternative explanation that is also consistent with the observations presented here is that sugars interact with agar, changing its properties and thereby preventing effective contact between slime and agar. At present there is no evidence that would clearly distinguish between the inhibitory effects of sugars being due to their interaction with slime or with agar, but one observation that favours the former hypothesis is that in all cases tested increasing concentrations of sugars led to decreased movement of individual cells away from the central mass. This was true for all gels tested whether colony spread was inhibited or not, suggesting that the cells themselves and not the gels are affected. But in either case, whether sugars interact with slime or with agar, the results reveal a cellular component that is required for translocation of motile cells. In order to function properly, this component must interact with the surface over which cells glide, and sugars interfere with the establishment of this interaction, depending on the nature of the surface being traversed.

Just how inhibitory sugars might interact with a surface slime to modify its properties and prevent colony spread is not understood. But if slime consists of heteropolysaccharides or glycoproteins such as those extracted from various gliding bacteria, possibilities exist for hydrogen bonding of neutral and charged sugars, ionic bonding of charged sugars, or even more specific kinds of interaction of sugars with glycoproteins. In this study a general lack of specificity was seen in the broad range of sugars that inhibit spread, but some degree of 
specificity is suggested by differences in effective concentrations for compounds in each of the three groups. Glucose is one of the group I inhibitors (most effective), and the other six inhibitors in this group and the two inhibitors in group II are derivatives of glucose molecules or disaccharides containing glucose, suggesting that these compounds might be more effective inhibitors due to their glucose moieties. However, the mere presence or absence of glucose is not sufficient to separate compounds into more effective and less effective inhibitors, since some group III compounds are also derivatives of glucose. Nevertheless, it is possible that stereochemical interactions required for the inhibition are more favourable with some glucose derivatives than with others. Lactose (group III) has glucose in a $\beta$-linkage to galactose, whereas all group I disaccharides have glucose in $\alpha$-linkages. Other group III glucose derivatives have bulky groups covalently linked to carbons 1 or 6 , or, in the case of sorbitol, the aldehyde group at carbon $I$ is reduced, thus preventing ring formation. In addition to bulky groups at carbons 1 or 6, glucose 6-phosphate, D-gluconic acid and D-glucuronic acid bear negative charges.

The exponential nature of the dose-response curve (Fig. 4) and inhibition by non-transported solutes suggest that sugars interact with specific sites on some extracellular component. The high concentrations required to inhibit suggest the presence of many sites per cell. Possible effects of sugars (or $\mathrm{Mg}^{2+}, \mathrm{Ca}^{2+}$ or $\mathrm{SO}_{4}^{2-}$ ) on an extracellular slime include altered water-binding properties of the slime, altered viscosity or altered interaction of polymer chains with each other (Rees, 1975). Any of these kinds of modifications might hinder the spread of slime over another surface.

Although the degree of inhibition of spread caused by sugars varied on different types of gels, one effect of sugars was seen on all gels tested : at increasingly higher concentrations of sugars, cells were packed into increasingly larger masses. But it is clear that the mere presence of sugars does not cause cells to clump, since cells did not clump together in broth cultures with up to $100 \mathrm{~mm}$-glucose or any of several other sugars. The different effects of sugars in broth and on surfaces can be explained by assuming that surface slime modified by complexing with sugars resists coating agar surfaces but is still water-soluble and capable of dispersal in broth. Why do sugars inhibit spread on $1.5 \%$ agar gels but not on $0.7 \%$ gels? There is reason to believe that cells of $C$. johnsonae cannot translocate directly over the surface of an agar gel but must first coat the agar surface with a slime and then move through the slime. The requirement for accumulation of slime may explain the adaptation period during which cells stop moving after being transferred from broth to an agar surface. Surfaces of $0.7 \%$ agar gels, in addition to having less polymer per unit area than do $1.5 \%$ gels, have more water that is not bound up in the agar gel. The surfaces of these gels are very moist, and it is difficult to detect motility of cells at edges of colonies on such gels because they are constantly in motion due to Brownian effects and vibrations transmitted through the microscope stage. These kinds of movements are probably responsible for the random arrangement of cells at the edges of these colonies (Fig. $9 e$ ). When sugars are added to these gels, the effect is similar to that on $1.5 \%$ agar gels in that increasing the concentration of sugar causes increasingly greater clumping of cells. Again, it appears as though cells are held together in a slime, but in the case of the $0.7 \%$ agar gel, slight clumping at low concentrations of sugar actually enhances colony spread. Perhaps the modified slime is unable to spread over the relatively dry surface of a $1.5 \%$ agar gel but can spread through the film of water covering the $0.7 \%$ agar gel.

A complex biological process such as gliding motility is made easier to investigate when it can be separated into two or more simpler components. The results reported here, along with results from earlier studies, allow us to distinguish two separate systems required for gliding motility of $C$. johnsonae. The two systems can be demonstrated experimentally. One system consists of all surface components necessary to bring about active movements of the cell surface, as demonstrated by the movement of latex spheres over the cell surface and by the spinning and somersaulting movements of individual cells (Pate \& Chang (1979). We refer to this system as the 'machinery' of motility. The nature of the machinery is as yet unknown, but one hypothesis is that it consists of a system of rotary motors, similar to those that turn bacterial flagella (Pate \& Chang, 1979). Another hypothesis to explain similar surface movements in a different Cytophaga species is that the machinery consists of sites on the outer membrane of the cell that 
move along tracks fixed to the peptidoglycan layer (Lapidus \& Berg, 1982). Whatever the nature of the machinery, a separate system is required to allow cells with moving surfaces to translocate over another surface, and the need for it in gliding motility is recognized in motile non-spreading mutants and in wild-type cells incubated with sugars, two experimental conditions that render cells with actively moving surfaces unable to translocate. The second system probably consists of surface polymer (slime).

Studies on the genetics of gliding motility of Myxococcus xanthus have shown the existence of at least two sets of genes controlling two separate systems of motility in that organism (Hodgkin $\&$ Kaiser, $1979 a, b$ ). Owing to many differences between $M$. xanthus and $C$. johnsonae and to differences in the experimental approaches used to define the two systems required for gliding, it is impossible at present to guess whether eventual elucidation of the cellular components underlying the two systems of each organism will reveal any relationships between them.

The failure to demonstrate a positive chemotactic response in $M$. xanthus (Dworkin \& Eide, 1983) or $C$. johnsonae is perhaps not surprising with hindsight. Gliding bacteria in general appear to have evolved for growth dependent upon competition for insoluble macromolecules. The relationship between the creeping style of movement and the ability to grow using a variety of polymers has long been recognized (Dworkin, 1966; Kaiser et al., 1979; Stanier \& Van Niel, 1941). Given the slow rates of surface translocation, and assuming that gliders are in fact specialized to compete for macromolecules rather than diffusible solutes as sources of nutrients, there would be no selective advantage in possessing a system enabling cells to respond to a spatial gradient of diffusible solutes. A more useful kind of behaviour for a bacterium that digests macromolecules while creeping over their surfaces might be one that ensures that cells are constantly moving away from the main mass of cells when nutrients are absent or below a certain critical concentration, and that somehow immobilizes the cells in areas where nutrients are plentiful. Immobilization of cells could be accomplished by $(a)$ repression of synthesis of motility machinery; (b) inhibition of operation of motility machinery; (c) alteration in the pattern of movements, say from directed movements away from the mass of cells to completely random movements; $(d)$ prevention of escape from the immediate area by somehow physically restraining the cells. The effects of sugars on colony spread of $C$. johnsonae on agar gels support a scheme such as this with immobilization being achieved by physical restraint of cells in a slime whose characteristics differ depending on the concentration of free sugars or sugars released by hydrolysis of polysaccharides. However, the inhibitory effects of sugars on colony spread may not occur in natural environments exactly as they occur on surfaces of $1.5 \%$ agar gels. Indeed, the responses vary among the limited number of gels tested in this study. But even though the effects of sugars on the rate of colony spread varied from one type of gel to another, their effects on the arrangement of cells at colony edges were always the same: increasing concentrations of sugars led to a decreasing ability of cells to escape the slime and leave the mass as single cells or small groups of cells.

Although the basis for the inhibitory effects of sugars on colony spread of $C$. johnsonae is not understood, and the importance of these effects in nature is unclear, it is interesting to note that inhibitory effects of nutrients on colony spread are common among the gliding bacteria (Burchard, 1974, 1981; Duxbury et al., 1980; Garnjobst, 1945; Henricksen, 1972; Stanier, 1946). The kinds of compounds that inhibit spread of colonies on agar surfaces vary from one gliding bacterium to another, and in most cases where observations of this nature have been reported it has not been established if cell motility or cell translocation was inhibited. Casamino acids added to concentrations between 0.1 to $2.0 \%$ supported good growth of cells of Flexibacter BH3 on a mineral salts agar medium but completely inhibited colony spread, whereas glucose, at concentrations up to $5 \%$ did not inhibit colony spread (Duxbury et al., 1980). It was not reported whether cells from non-spreading colonies on the Casamino acid plates were motile. As with $C$. johnsonae, $\mathrm{Mg}^{2+}$ and $\mathrm{Ca}^{2+}$ inhibited colony spread, and $\mathrm{Ca}^{2+}$ but not $\mathrm{Mg}^{2+}$ inhibited growth at concentrations required to inhibit spread. Unlike the case with $C$. johnsonae (Chang \& Pate, 1981), the monovalent cations $\mathrm{K}^{+}$and $\mathrm{Na}^{+}$inhibited colony spread at $0.1 \mathrm{M}$ concentrations. The effects of cations on the motility of the cells were determined by microscopically observing cells in a dialysis microchamber while the concentrations of salts in the 
microchamber were adjusted. It was reported that $0 \cdot 1 \mathrm{M}-\mathrm{K}^{+}, \mathrm{Mg}^{2+}$ and $\mathrm{Ca}^{2+}$ inhibited motility of the cells. But $0 \cdot 1 \mathrm{M}-\mathrm{Na}^{+}$appeared to render most cells incapable of adhering to the surface; whenever a cell was seen attached to a surface it was capable of movement, suggesting to the authors that the presence of $\mathrm{Na}^{+}$somehow modified the physical properties of the slime so that it no longer served as an effective temporary adhesive. This is the only other report we are aware of in which it was demonstrated that a solute inhibited colony spread of a gliding bacterium without affecting its motility. Stanier (1946) noted that colonies of $C$. johnsonae growing on peptone media varied in appearance depending on peptone concentration : at concentrations of $1.0 \%$ or lower, typical myxobacterial spreading colonies were obtained, and higher concentrations of peptone resulted in non-spreading colonies. He concluded that the high proteinaceous content of some nutrient media inhibit cell motility. In the present study and in an earlier report (Chang \& Pate, 1981) colony spread of $C$. johnsonae was inhibited by increasing the concentration of tryptone in EC agar, but individual amino acids or Casamino acids failed to decrease colony spread at any concentration. Commercial peptones and tryptones contain sugars as well as amino acids, and at the inhibitory levels used, the concentration of sugars might be sufficiently high to inhibit colony spread.

It is impossible at present to do more than speculate on the importance of the inhibitory effects on translocation caused by certain solutes in the natural history of these bacteria, but the phenomenon described here may prove useful in attempts to identify and characterize components of a slime required by cells of $C$. johnsonae for surface translocation. Our inability to isolate mutants whose colony spread is not inhibited by sugars, suggests that any mutant deficient in a surface polymer whose properties are affected by sugars would be unable to spread, and therefore could not be detected. Some of the motile, non-spreading mutants alluded to earlier may be unable to translocate over an agar surface due to their inability to produce the slime that, in wild-type cells, is modified upon addition of sugars. Thus, comparison of slime material from such mutants with that of wild-type cells may aid in identifying the component necessary for colony spread. Once a candidate for this role is identified and isolated, characterization of its properties (e.g. hydration, swelling of gel, binding of sugars, viscosity) in the presence and in the absence of sugars should lead to an understanding of the molecular basis for the inhibition of colony spread by various solutes.

This research was supported by the College of Agricultural and Life Sciences, University of Wisconsin, Madison, and by grant PCM-790491 3 from the National Foundation of Science. We are grateful to Brian Yandell and Brad Schultz of the Department of Statistics for consultations on statistical analyses.

\section{REFERENCES}

ADLER, J. (1975). Chemotaxis in bacteria. Annual Reriew of Biochemistry 44, 341-356.

Arlauskas, J. \& Burchard, R. P. (1982). Substratum requirements for bacterial gliding motility. Archices of Microbiology 133, 137-141.

BRADFORD, M. (1976). A rapid and sensitive method for the quantitation of microgram quantities of protein utilizing the principle of protein-dye binding. Analytical Biochemistry 72, 248-253.

Bretscher, A. P. \& Kaiser, D. (1978). Nutrition of Myxococcus xanthus, a fruiting myxobacterium. Journal of Bacteriology 133, 763-768.

BURCHARD, R. P. (1974). Growth of surface colonies of the gliding bacterium Myxococcus xanthus. Archices of Microbiology 96, 247-254.

BuRchard. R. P. (1981). Gliding motility of prokaryotes: ultrastructure, physiology, and genetics. Annual Review of Microbiology 35, 497-529.

BurChaRd, R. P. (1982). Trail following by gliding bacteria. Journal of Bacteriology 152, 495-501.

Chang, L.-Y. E. (1982). Studies on gliding motility in Cyrophaga johnsonae. PhD thesis, University of Wisconsin, Madison, USA.
Chang, L.-Y. E. \& Pate, J. L. (1981). Nutritional requirements of Cytophaga johnsonae and some of its auxotrophic mutants. Current Microbiology S, 235 240.

Christensen, P. J. (1977). The history, biology and taxonomy of the Cytophaga group. Canadian Journal of Microbiology 23, 1599-1653.

DuXbury, T., Humphrey, B. A. \& Marshall, K. C. (1980). Continuous observations of bacterial gliding motility in a dialysis microchamber: the effects of inhibitors. Archices of Microbiology 124, 169175.

Dworkin, M. (1966). Biology of the Myxobacteria. Annual Review of Microbiology' 20, 75-106.

DWorkIN. M. \& EIDE, D. (1983). Myxococcus xanthus does not respond chemotactically to moderate concentration gradients. Journal of Bacteriology 154 . 437-442.

GARNJOBST, L. (1945). Cyrophaga columnaris (Davis) in pure culture: a myxobacterium pathogenic to fish. Journal of Bacteriology 49. 113-128.

Glaser, J. \& PATE, J. L. (1973). Isolation and characterization of gliding motility mutants of 
Cytophaga columnaris. Archiv für Mikrobiologie 93. 295-309.

HenRicksen, J. (1972). Bacterial surface translocation: a survey and a classification. Bacteriological Reriews 36. 478-503.

Ho, J. \& MCCURDY, H. D. (1979). Demonstration of positive chemotaxis to cyclic GMP and 5'-AMP in Myxococcus xanthus by means of a simple apparatus for generating practically stable concentration gradients. Canadian Journal of Microbiology 25. 1214 1218.

HODGKIN, J. \& KAISER, D. (1979a). Genetics of gliding motility in Myxococcus xanthus (Myxobacterales): genes controlling movement of single cells. Molecular and General Genetics 171, 167-176.

HODGKIN, J. \& KAISER, D. (1979b). Genetics of gliding motility in Myxococcus xanthus (Myxobacterales): two gene systems control movement. Molecular and General Genetics 171, 177-191.

Humphrey, B. A., Dickson, M. R. \& Marshall, K. C. (1979). Physiochemical and in situ observations on the adhesion of gliding bacteria to surfaces. Archices of Microbiology 120, 23i-238.

Johnson, J. L. \& Chitton, W. S. (1966). Galactosamine glycan of Chondrococcus columnaris. Science 152, $1247-1248$.

Kaiser, D. Manoll, C. \& Dworkin, M. (1979). Myxobacteria: cell interactions, genetics, and development. Annual Review of Microbiology 33. 595-639.

LAPIDUS, I. R. \& Berg, H. C. (1982). Gliding motility of Cytophaga sp. strain U67. Journal of Bacteriology 151, 384-398.

LEV, M. (1954). Demonstration of a diffusible fruiting factor in Myxobacteria. Nature, London 173, 501.
McVittie, A. \& Zahler, S. A. (1962). Chemotaxis in Myxococcus. Nature, London 194, 1299-1300.

Pate, J. L. \& Chang, L.-Y. E. (1979). Evidence that gliding motility in procaryotic cells is driven by rotary assemblies in the cell envelopes. Current Microbiology 2, 59-64.

Pate, J. L., Petzold, S. J. \& Chang, L.-Y. E. (1979). Phages for the gliding bacterium Cytophaga johnsonae that infect only motile cells. Current Microbiology 2. 257-262.

REES, D. A. (1975). Stereochemistry and binding behavior of carbohydrate chains. In Biochemistry of Carbohydrates, pp. 1-42. Edited by W. J. Whelan. Baltimore. Md.: University Park Press.

Shimkets, L. J., DWorkin, M. \& Keller, K. H. (1979). A method for establishing stable concentration gradients in agar suitable for studying chemotaxis on a solid surface. Canadian Journal of Microbiology 25, 1460-1467.

Stanier, R. Y. (1946). Studies on nonfruiting myxobacteria. I. Cytophaga johnsonae, n. sp., a chitindecomposing myxobacterium. Journal of Bacteriology 53, 297-315.

Stanier, R. Y. \& Van Niel, C. B. (1941). The main outlines of bacterial classification. Journal of Bacteriology' 42, 437-446.

Sutherland, I. W. (1979). Polysaccharides produced by $C_{y}$ 'stobacter, Archangium, Sorangium and Srigmatella species. Journal of General Microbiology 111 , 211-216.

Sutherland, I. W. \& Thomson, S. (1975). Comparison of polysaccharides produced by Myxococcus strains. Journal of General Microbiology 89, 124-132. 